\title{
Stability of ABR Wave V Threshold in Early Hearing Diagnostics in Children from Selected Groups at Risk of Congenital Hearing Loss
}

Authors' Contribution: A-Study Design B-Data Collection

C-Statistical Analysis

D-Manuscript Preparation

E-Literature Search

F-Funds Collection

\author{
Sebastian Kocoń ${ }^{\text {ABDEFC }}$, Konrad Skórkiewicz ${ }^{2 C}$, Paweł Stręk ${ }^{1 \mathrm{E}}$, Jacek Składzieńn ${ }^{1 \mathrm{E}}$, Patryk Hartwich ${ }^{1 \mathrm{EC}}$, \\ Remigiusz Ziarno ${ }^{1 \mathrm{EF}}$, Jerzy Tomik ${ }^{1 \mathrm{DE}}$
}

'Chair and Clinic of Otolaryngology, Jagiellonian University, Collegium Medicum, Cracow, Poland; Head: prof. Jacek Składzień MD PhD ${ }^{2}$ Faculty of Physics, Astronomy and Applied Computer Science, Jagiellonian University, Cracow, Poland

Introduction: Upon hearing that the "little" patient has trouble with hearing, we are mostly interested in the level of his hearing threshold. When the child is in the first year of life, results can only be achieved by means of ABR test. Subsequent control tests, especially in children from the hearing loss risk groups selected in this study, show that the obtained outcomes are subject to fluctuations. Their fluctuating nature is manifested by the instability of wave $V$ threshold in subsequent diagnostic periods. Such variability often delays the implementation of the appropriate proceeding. Knowledge of the dissimilarity of behavior of the wave $V$ threshold occurring in individual groups at risk of hearing loss allows for the correct interpretation of the obtained results, and thus, effective therapeutic measures.

Aim: The aim of the paper is to analyze the stability of wave $V$ threshold during the first year of life in children from selected risk groups for congenital hearing disorders.

Material and methods: From the patient population of 2,114 individuals examined in 2015-2016 at a reference center participating in the Universal Neonatal Hearing Screening Program in 2015-2016, the results of 250 children were subjected to retrospective analysis. Furthermore, 4 groups of little patients were formed (children with Down syndrome; children with other diseases or damage to the nervous system; children with cleft palate or cleft lip and cleft palate; children with congenital cytomegaly) in whom diagnostic practice revealed variable results of the wave $V$ threshold. We analyzed the results of tests obtained during the first year of the child's life divided into 4 diagnostic periods.

Results: The highest percentage of instability in the established threshold of wave $V$ between individual diagnostic periods occurred in the group of children with cleft palate or cleft lip and cleft palate. In the group of children with Down syndrome, it was observed that the instability of the ABR test results decreased over time. In the group of children with other diseases or damage of the nervous system, the highest percentage of the lack of stable $A B R$ wave $V$ thresholds was observed between the $1 s t$ and 2 nd as well the 1st and 4th diagnostic periods. On the other hand, in the group of children with congenital CMV, there was a relatively low percentage of instability of results.

Conclusions: (1) Although the ABR test is a diagnostic standard, in particular groups of patients the study is burdened with high variability of measurement results in subsequent diagnostic periods. Such a group of patients are children with cleft palate or cleft lip and cleft palate; therefore, it must receive particular attention in treatment planning; (2) in selected groups at risk of hearing loss, due to the high percentage of children with hearing impairment (70\%), the validity of performing newborn hearing screening tests was confirmed.

\section{ABBREVIATIONS}

ABR - auditory brainstem response

AI - impedance audiometry

FDP - Low Pass Filter

FGP - High Pass Filter

PPPBSN - Program for Universal Hearing Screening in Newborns

SNR - signal-to-noise ratio

TEOAE - transient-evoked otoacoustic emission

\section{INTRODUCTION}

It has been argued that hearing problems in newborns are one of the most common irregularities in this period of life [1-3]. According to the data of the Great Orchestra of Christmas Charity, in the group of children aged 0 to 5 , which is the most important period for speech development, as much as $90 \%$ of permanent damage is congenital [4]. Only half of children with congenital hearing impairment have risk factors for hearing impairment. This means that without appropriate examinations, 


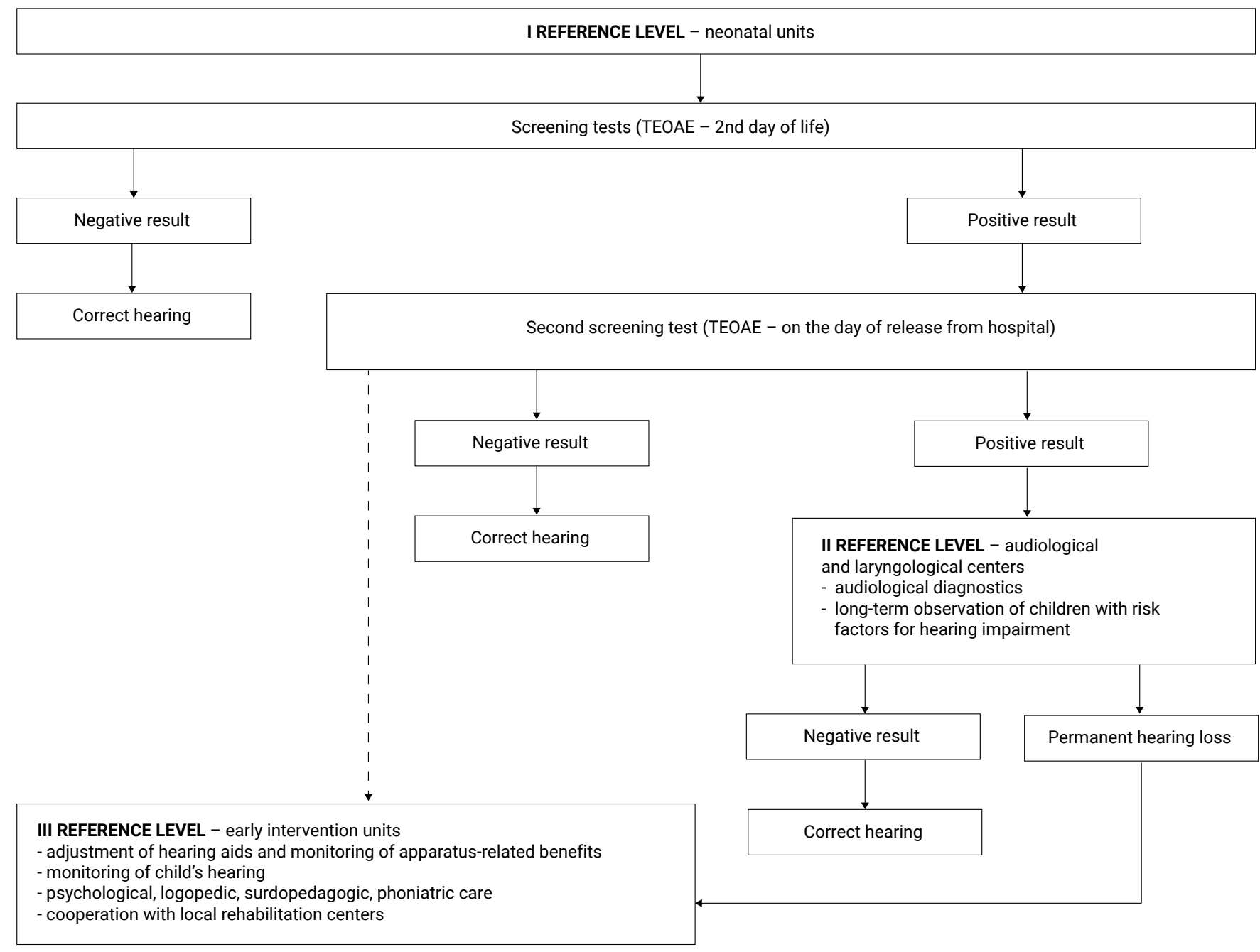

Fig. 1. General protocol for patients included in the Universal Hearing Screening Program [10].

in these cases neither the doctors nor the parents have grounds to suspect the existence of a hearing problem in the child $[5,6]$.

In Poland, work on the standardization of screening procedures and their forms were carried out by the Diagnostic-Treatment-Rehabilitation Center for the Deaf and Hearing Impaired "Cochlear Center", as well as the Institute of Physiology and Pathology of Hearing in Kajetany in 1995-1997.

Based on those studies, it was assumed that the best method of screening newborns' hearing in the daily practice of neonatal departments is transient-evoked otoacoustic emissions (TEOAE) with click stimuli, followed by ABR test [7]. The TEOAE technique was chosen for the following reasons:

- medical, as it is very effective in detecting hearing loss in children at such an early stage of life. Otoemission caused by click stimuli is already recorded in patients with hearing loss of less than 30-35 dB nHL. It is also argued that in subjects without hearing loss, click-evoked otoemission is present in almost $100 \%$ of cases;

- logistical and practical resulting from practicability of the test, the speed of performing the test and a short training period for the personnel performing the test. An advantage is that it does not require stringent local requirements to be met by neonatal departments performing the test - no silence cabin or protection against electromagnetic interference are required.

TEOAE is done on the second day of a child's life. In the event of a positive result (abnormal hearing), the examination is repeated on the date of leaving the hospital. During the child's stay in the neonatal unit, the staff collects information on risk factors affecting the child's hearing $[1,2]$.

Children with a positive screening result (hearing impairment) and children from so-called risk groups are referred to reference centers for further diagnosis and observation. Children at risk are referred to the above-mentioned centers even if the screening test result is negative (i.e. normal hearing).

The risk group of hearing disorders includes [3, 5, 7-9]:

- children with a family history of hearing impairment,

- children with a head and neck congenital anomaly,

- early babies < 33 hbd (week of pregnancy), 


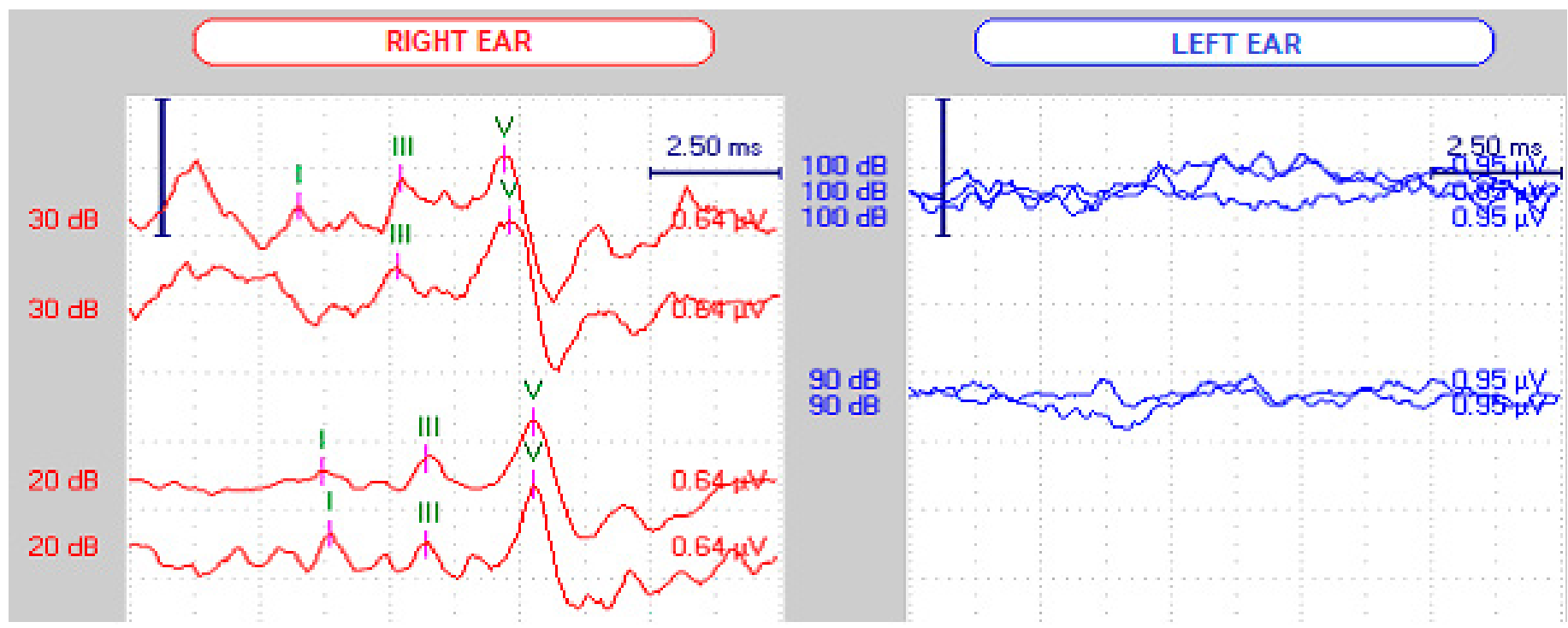

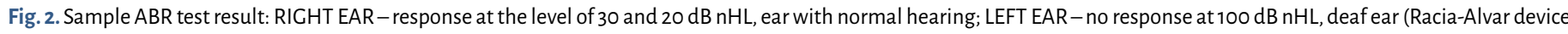
with Centor $($ ver. 5.48PL).).

- children whose mother was infected with TORCH during pregnancy (toxoplasmosis, influenza virus, measles, Coxsackie viruses, B19 virus, rubella, cytomegaly, herpes virus),

- children who were administered ototoxic drugs after birth or whose mothers took ototoxic drugs during pregnancy,

- children diagnosed with jaundice requiring a transfusion at birth,

- children with a history of meningitis,

- children who were connected to the artificial ventilator $>5$ days,

- children who required intensive care $>7$ days,

- children with impaired or absent vestibulo-ocular reflex $70 \mathrm{~dB}$,

- children with birth defects associated with hearing loss (genetic defects, neurological disorders, etc.),

- children with negative results of the hearing screening test in the hospital (no correct otoacoustic emission was registered).

Upon hearing that the "little" patient has trouble with hearing, we are mostly interested in the level of his hearing threshold. When the child is in the first year of life, we can only achieve results by means of ABR test. However, it turns out that subsequent control tests, especially in children from the hearing loss risk groups selected in this study, produce variable, fluctuating results. This is usually manifested by the instability of wave $\mathrm{V}$ threshold in subsequent diagnostic periods, which often leads to extending the implementation time of the appropriate proceedings.

It seems, however, that knowing certain patterns regarding the wave $\mathrm{V}$ threshold occurring in individual groups at risk of hearing loss, we are able to assume with a high degree of probability the reason behind variable results in such a case, and thus attempt to implement effective measures.

\section{AUDITORY BRAINSTEM RESPONSE-ABR}

A study involving the recording of biopotentials in the auditory nerve and brainstem in response to an acoustic stimulus. In clinical practice, this test found application in assessment of the hearing threshold, differential diagnosis (determination of the type of hearing loss), screening of hearing in newborns and infants, and monitoring of auditory nerve and brain stem function during neurosurgical procedures $[6,11]$.

Due to the non-invasive nature of the test, ABR is performed in children from the first months of life. This test is also carried out in people with mental retardation, in whom it is not possible to conduct subjective and behavioral tests. This method is also used as a supplement to other previously performed objective tests (otoacoustic emission, impedance audiometry).

The electrical activity of auditory areas within the brainstem is recorded by electrodes which are placed:

- on the surface of the head, preferably at the top. Due to the presence of hair in this part of the head, the electrode is stuck to the patient's forehead - it is an active, positive electrode,

- the second electrode is stuck to the mastoid or the earlobe of the side of the tested ear - it is a reference electrode, negative,

- the third electrode is stuck to the mastoid or the ear lobe of the opposite ear - it is a grounding electrode $[7,12]$.

The recorded response in the ABR test consists of several waves marked with Roman numerals.

Areas of generation of individual waves:

- wave I - distal portion of the auditory nerve,

- wave II - proximal portion of the auditory nerve, 
- wave III - cochlear nucleus,

- wave IV - superior olivary complex,

- wave V - lateral lemniscus.

In audiological practice, the most frequently used identification is that of three registered characteristic waves occurring in this record, i.e. waves I, III, V, and the measurement of their latency and intervals between them [7, 12-14].

The error in the determination of hearing threshold established on the basis of wave $\mathrm{V}$ using a correctly performed ABR test usually does not exceed $10 \mathrm{~dB}$. Therefore, this value is taken as the permissible measurement error.

The ABR test in children, and in particular in those whose results were analyzed in this study, i.e. before 1 year of age, is performed during sleep. The sleep of a little patient is an essential condition to obtain a meaningful input signal. In a situation where the child does not fall asleep due to disturbances generated by the little patient (crying, excessive mobility), the obtained results are unreliable and the test is repeated. In most centers, the sleep of a little patient is physiological, and thus the parents guardians are required to properly prepare their child. When establishing the date of ABR, parents/guardians are instructed about what happens at the assessment and how it is carried out. Furthermore, the child's parents/guardians receive detailed written instructions.

Some centers use pharmacological agents, e.g. chlorate hydrate in the form of rectal enemas, in order to avoid difficulties resulting from obtaining physiological sleep in young children. However, when it comes to using pharmacological agents during ABR, an earlier opinion of a pediatrician or family doctor regarding the child's health condition is required, or in the case of full anesthesia, the presence of an anesthesiologist, which is a major impediment for medical centers, clinics without hospital status or without an anesthesiologist [14].

\section{PURPOSE}

The purpose of the paper is to analyze the stability of wave $\mathrm{V}$ threshold during the first year of life in children from selected risk groups for congenital hearing disorders.

\section{MATERIAL AND METHODS}

\section{Inclusion criteria for patients}

From a population of 2,114 patients tested in the years 2015-2016 at the reference center participating in the Universal Neonatal Hearing Screening Program of the Specialist Center of Diagnosis and Rehabilitation for Children and Adolescents with Hearing Disabilities of the Polish Association of the Deaf in Krakow, the results of 250 children were subjected to retrospective analysis. Of these selected patients, 138 are girls and 112 are boys. The study group consisted of children from one to three months of age. The results of examinations of patients from the group at risk of hearing loss were analyzed. Additionally, we created 4 groups of little patients, who presented variable results of wave $V$ threshold in diagnostic practice. Inclusion of a patient in a given group was based on the test results provided by neonatal departments and a questionnaire completed by the ENT specialist during the patient's first visit to the center.

The results of tests obtained during the first year of the child's life were then analyzed; this related to the ABR test with click stimuli. Due to the high ratio of interference/artifact, the ABR test with stimulus in the form of tones of $500 \mathrm{~Hz}$ and $1000 \mathrm{~Hz}$ was not analyzed.

The first year of a child's life was divided into 4 diagnostic periods:

- 1st diagnostic period 1-3 months of the child's life,

- 2nd diagnostic period 4-6 months of child's life,

- 3rd diagnostic period 7-9 months of child's life,

- 4th diagnostic period 10-12 months of child's life.

Groups of children included in the study:

1. Children with Down syndrome - hearing loss is observed in over $60 \%$ of children in this group. Hearing loss is usually conductive due to the presence of a narrow Eustachian tube and muscle hypotension, which causes more frequent accumulation of secretions, and more common infections of the upper and lower respiratory tract. Sensorineural or mixed hearing loss is less prevalent in this group [15];

2. Children with other diseases or damage to the nervous system - this group includes children diagnosed with damage to the nervous system after birth (hypoxic-ischemic encephalopathy, meningitis, hypertonia, hydrocephalus, cerebral palsy, epilepsy, other neurodegenerative diseases), as well as children whose final neurological diagnosis was not known at the time of audiological diagnosis, however, there was a serious suspicion of disease or damage to the nervous system (low Apgar score, low birth weight, intensive therapy, artificial ventilation. In the course of neurological diseases, the symptoms often indicate a possible damage to the auditory receptor and/or the auditory pathway. However, in neurological conditions, hearing loss is a relatively rare disease symptom and is very uncommonly the leading manifestation of a neurological disease, and usually a component of a particular symptom complex. Children with neurological diseases practically never have hearing impairments in case of damage at the cortical level, but those sometimes occur in damage to the brainstem. The largest group of hearing impairment in neurological diseases occurs in the course of vascular disorders in the central nervous system. Such disorders often take place in childbirth, when there is a hypoxic-ischemic encephalopathy, asphyxia. Intensive therapy and artificial ventilation are also necessary in premature and /or low birth weight children with a low Apgar score. Neonatal asphyxia can be associated with damage to the inner ear and the outer hair cells in the organ of Corti may disappear. There is a reasonable suspicion that these particular children may develop hearing problems $[5,16]$; 
Tab. I. Summary of TEOAE screening results in the neonatal unit.

\begin{tabular}{|c|c|c|}
\hline TYPE OF CONDITION & $\begin{array}{l}\text { NUMBER AND PERCENTAGE OF ANALYZED } \\
\text { CHILDREN }\end{array}$ & $\begin{array}{l}\text { NUMBER AND PERCENTAGE OF CHILDREN } \\
\text { WITH ABNORMAL (POSITIVE) RESULTS OF } \\
\text { TEOAE SCREENING }\end{array}$ \\
\hline Children with Down syndrome & $62(24,8 \%)$ & $58 / 62(93,5 \%)$ \\
\hline Children with other diseases or damage to the nervous system & $66(26,4 \%)$ & $58 / 66(87,5 \%)$ \\
\hline Children with cleft palate or cleft lip and cleft palate & $54(21,6 \%)$ & $35 / 54(64,8 \%)$ \\
\hline Children with congenital cytomegaly & $68(27,2 \%)$ & $27 / 68(39,4 \%)$ \\
\hline Conclusion & $250(100 \%)$ & $176 / 250(70 \%)$ \\
\hline
\end{tabular}

3. Children with cleft palate or cleft lip and cleft palate - due to the distinctive anatomical features of the developmental defect in question, the suspicion of its presence is put forward already in the delivery room or in the neonatal unit, therefore classification of the child in this group was based on the diagnosis obtained from the neonatal unit. Due to the abnormal function of the Eustachian tube, this group of patients is accompanied by a conductive component of hearing loss, which increases the hearing threshold. The cause of disturbances in the ventilation on Eustachian tube is failure of the muscles of the cleft palate. It is estimated that this group of patients is affected by conductive hearing loss in up to $50 \%$, while sensorineural hearing loss is rare. The timing of surgery to close a cleft palate is of immense importance. It is believed that prior closure of the cleft palate reduces the risk of hearing loss. Based on the literature, it can be concluded that patients who underwent surgery before the age of 1 were affected by hearing loss only in about $10 \%$ of cases, while in the case of later surgery, there were almost $60 \%$ of cases with hearing loss $[17,18]$;

4. Children with congenital cytomegalovirus infection - the child was counted as part of this group on the basis of the diagnosis obtained from the neonatal unit and positive results of the antibody test (IgG, IgM) delivered during audiological diagnosis. The degree of unilateral or bilateral hearing loss resulting from the effects of cytomegalovirus on the organ of hearing may change during the child's development. The virus enters numerous organs with blood and remains in the so-called latent phase of infection; it reactivates when immunity declines. Reduced sense of hearing may occur later than immediately after birth, and it may also progress. Therefore, even after preliminary audiological tests determining the child's hearing as normal, periodic check-ups should not be discontinued until the age of $6[19,16,20]$.

\section{Inclusion criteria for patients from control group}

The study group did not include children who, despite having hearing problems and classified as at risk of hearing loss, did not have the features of the above-mentioned 4 groups. The study group also did not include the test results of those children whose parents/guardians changed the diagnostic center during diagnosis. The results of examinations of children who died during the diagnostic period were not included in the study group.

\section{Criteria for evaluation of results}

\section{TEOAE}

In the TEOAE study used in screening tests, as well as in tests at reference centers, the result is recorded in the form of an approved or rejected test, i.e. we accept as follows:

- negative result - test approved - the message "PASS" is displayed, which means that a correct otoacoustic signal has been registered - correct hearing;

- positive result - test rejected - the message "REFER" is displayed, indicating that a valid otoemission signal was not recorded - hearing loss suspected.

\section{ABR (clickstimuli)}

Negative result: registering a wave $\mathrm{V}$ with correct latency for a stimulus with an intensity of $\leq 30 \mathrm{~dB} \mathrm{nHL}$ (the adopted standard: for $20 \mathrm{~dB}$ wave V latency - 7.9-9.0 ms; for $30 \mathrm{~dB}$ wave V latency - 7.3-8.1 ms). Positive result: wave V threshold greater than $35 \mathrm{~dB}$ nHL.

\section{Technical parameters of the devices used in the research}

1. Impedance audiometry was performed on Interacoustics AT 235 equipment:

- Pressure range $+225 /-400 \mathrm{dPa}$,

- Measuring tone frequency $226 \mathrm{~Hz}$ or $1000 \mathrm{~Hz}$,

- Upper limit of norm for compliance $-1.5 \mathrm{ml}$;

2. TEOAE testing was performed on Interacoustics OtoReaddevice with Database ver. 7.70.1. The TEOAE test protocol settings were as follows:

- Number of test frequencies $=6$,

- Averaging time $=64$ seconds,

- Frequency range $=1.5 \mathrm{kHz}$ to $4 \mathrm{kHz}$,

- SNR (signal-to-noise ratio) for NORMAL (PASS) $=4 \mathrm{~dB}$,

- Click-presentation level = $83 \mathrm{~dB}$,

- Number of frequencies passed to pass the entire test to "NORMA" (PASS) = 4;

3. ABR - the test was performed on a Racia-Alvar device with software Centor C ver. 5.48PL. Test parameters:

- Type of stimuli - a click with a duration of $100 \mu \mathrm{s}$,

- Short tone with Gaussian envelope, 
Tab. II. Percentage of the results of ABR in children from selected risk groups for congenital hearing impairment, in which the difference in the established threshold of wave $V$ compared to the previous test and between periods 1 st and 4 th was greater than $20 \mathrm{~dB}$.

\begin{tabular}{|c|c|c|c|c|c|}
\hline TYPE OF CONDITION & I-II [\%] & II-III [\%] & III-IV [\%] & HIV [\%] & $\begin{array}{l}\text { AVERACE ANNUAL } \\
\text { VOLATILITY } \\
\text { WITH STANDARD } \\
\text { DEVIATION [\%] }\end{array}$ \\
\hline Children with Down syndrome & 30 & 40 & 30 & 20 & $30 \pm 8$ \\
\hline $\begin{array}{l}\text { Children with other diseases } \\
\text { or damage to the nervous system }\end{array}$ & 32 & 20 & 16 & 28 & $24 \pm 7$ \\
\hline Children with cleft palate or cleft lip and cleft palate & 34,8 & 47,8 & 60,9 & 52,2 & $50 \pm 11$ \\
\hline Children with congenital cytomegaly & 16,1 & 9,7 & 3,2 & 9,7 & $10 \pm 5$ \\
\hline
\end{tabular}

- Duration of short tone -5 periods,

- Amplifier sensitivity $-50 \mu \mathrm{V} / \mathrm{V}$,

- FGP - $160 \mathrm{~Hz}$; FDP - $1.6 \mathrm{kHz}$,

- Masking - broadband noise (-30 dB),

- Plateau time - $0 \mathrm{~ms}$,

- Stimulus polarity - alternating,

- Transducer type: DT 48 headphones from Beyer Dynamik,

- Analysis time - $12.5 \mathrm{~ms}$,

- Triple repetition of registration of responses for a stimulus of the same intensity,

- Hearing threshold criterion - the lowest stimulus intensity at which there was double response of wave $\mathrm{V}$,

- Applied stimulus level - from 20 to $95 \mathrm{~dB}$ nHL in $10 \mathrm{~dB}$ step,

- Permissible error in establishing the hearing threshold determined on the basis of the $10 \mathrm{~dB}$ wave $\mathrm{V}$,

- Electrode placement: (1) positive - high forehead, (2) negative - mastoid of examined ear, (3) grounding - mastoid of opposite ear.

We used the Statistica software to calculate the basic data of descriptive statistics - the arithmetic mean of the annual variability for the studied groups of patients was calculated along with the confidence interval for the determined means at the level of $95 \%$. Student's tdistribution was used for the sample of $n=4$ (4 measurement periods) during determination of the confidence interval. The obtained results were subjected to statistical analysis. The assumed level of significance was $\mathrm{p}<0.05$.

The study was approved by the Bioethics Committee of the Jagiellonian University CM KBET/131/B2013.

\section{RESULTS}

The result of the TEOAE screening test performed in the neonatal unit was used as the initial test of the child's hearing. The study group consisted of 250 "little" patients with diseases described in point 2, constituting the so-called risk group for congenital hearing loss.

The further study included 176 patients enrolled based on TEOA screening. In order to observe the stability of wave $\mathrm{V}$ threshold determined in ABR over the first year of the patient's life, it was divided into 4 diagnostic periods (I-IV). The diagnostic periods were closely related to the patient's life expectancy:
- 1st diagnostic period 1-3 months of child's life,

- 2nd diagnostic period 4-6 months of child's life,

- 3rd diagnostic period 7-9 months of child's life,

- 4th diagnostic period 10-12 months of child's life.

During the diagnostic periods, the patients underwent an ABR examination. Based on the study, we determined and compared the percentage of results in which the difference of the established threshold of wave $\mathrm{V}$ compared to the study conducted in the previous diagnostic period was greater than $20 \mathrm{~dB}$ (Tab. II.). The results of ABR between the 1st and 4th study periods were also analyzed.

\section{BIOSTATISTICALANALYSIS}

For the 1st and 2nd diagnostic period, for all selected groups it was observed that, with the exception of the group of children with congenital cytomegalovirus, this percentage oscillated between $30-34.8 \%$. On the other hand, in the group of children with congenital CMV this percentage was $16.1 \%$. When analyzing the 2 nd and 3 rd diagnostic periods, it was noted that the highest percentage of children with a hearing threshold change of more than $20 \mathrm{~dB}$ were those with a cleft palate or cleft palate and cleft lip $-47.8 \%$. In the group of children with Down's syndrome, this percentage was $40 \%$. In the remaining analyzed groups, this share was $20 \%$ for children with other diseases or damage to the nervous system, and in the group of children with congenital CMV it was $9.7 \%$. In the 3rd and 4th diagnostic periods, the highest percentage of unstable results was observed in the group of children with cleft palate or cleft palate and cleft lip - 60.9\%. On the other hand, for the group of children with Down's syndrome this percentage decreased to $30 \%$. In the group of children with other diseases or damage to the nervous system, this percentage was $16 \%$. For children with congenital cytomegaly, unstable results during this period were observed in $3.2 \%$ of patients.

Verification of the mean annual changes showed that in the group of children with cleft palate or cleft palate and cleft lip, the highest frequency of changes was $50 \%$. The lowest mean of the annual variable was found in children with congenital CMV, amounting to $10 \%$. Also, between these groups it was observed that the results of mean changes, apart from significant algebraic differences, are statistically significant with the assumed significance level $\mathrm{p}=0.05$ (see Chart 2). In the remaining cases, no significant statistical differences were observed. 


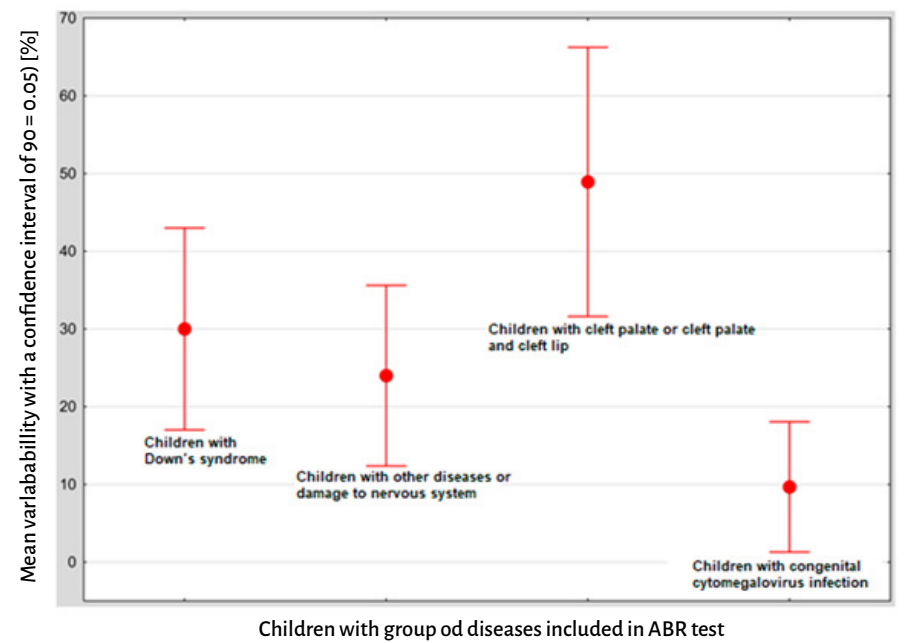

Fig. 3. Summary of the mean changes in the threshold of wave $V$ between the research periods together with the confidence intervals with the assumed $p=0.05$ for individual groups of studied children.

\section{DISCUSSION}

Thanks to the Program for Universal Hearing Screening in Newborns (PPPBSN), early detection of hearing loss in Poland is now a standard, which not only ENT doctors, but also pediatricians or family doctors perceive as something common. This standard includes: screening of child on the 2nd day after birth, and in the event of a hearing problem (positive result), the test is repeated before the child is released home from the neonatal unit $[2,10]$. Next, the children with a positive result, as well as those who belong to the so-called groups at risk of hearing loss, are referred to centers where further hearing diagnostics are performed. At this stage of the child's hearing monitoring, in addition to the repeated TEOAE test, other diagnostic methods are used, such as impedance audiometry (AI), and also to determine the hearing threshold potentials evoked from the brainstem (ABR - auditory brainstem responses) [21,22].

As an objective method, ABR allows to effectively determine the scale of a hearing problem and directs the implementation of further procedures. Unfortunately, it has been observed that a major concern in audiological diagnosis, especially in the groups of children selected for this work, is the instability of obtained results [5, 23-25].

The analysis conducted in this paper allowed to determine, that the largest share of instability in the established wave $\mathrm{V}$ threshold between individual diagnostic periods occurred in the group of children with cleft palate or cleft palate and cleft lip. As already mentioned, in these children the emerging factors related to a developmental defect have a considerable impact on the level and quality of hearing in these children, and thus on the results of subsequent studies. That said, in the group of children with Down syndrome, we observe that the instability of ABR test results decreases over time, which enables the attending physician to draw appropriate diagnostic conclusions and implement appropriate measures [15]. In the group of children with other diseases or damage to the nervous system, it is worth noting that the highest percentage of the lack of stable thresholds for wave $\mathrm{V}$ in the ABR study was observed between the 1st and 2nd as well as between the 1st and 4th diagnostic periods. Therefore, the results of this observation indicate that in the 1st diagnostic period, children from this group repeatedly obtained results which to a large extent required checking and repetition of test. On the other hand, in the group of children with congenital cytomegalovirus, there was a relatively low percentage of results instability [23]. Noteworthy is the comparison of results of the determined threshold of wave $\mathrm{V}$ from the 1 st and 2 nd periods where this percentage was the highest. The plausible cause for this could be the influence of other factors not directly related to the risk factor for hearing loss, such as other emerging diseases (infections), development of the nervous system, or the wave $\mathrm{V}$ threshold obtained in the first ABR study.

During the study, in selected groups at risk of hearing loss we also observed that due to the high percentage of children with hearing impairment, as much as $70 \%$, it is reasonable to perform newborn hearing screening. It was also concluded that although the ABR test is a diagnostic standard nowadays, in some groups of patients, especially in children with cleft palate or cleft palate and cleft lip, this test is burdened with high variability of measurement results in subsequent diagnostic periods. Therefore, it leads to an incorrect determination of the actual hearing threshold in the early diagnostic period and, consequently, to the extension of the correct final diagnosis [21]. Not only is the diagnostic time lengthening, but also the moment of introducing the final procedure. Knowing this fact, doctors dealing with this group should analyze the planned treatment in a particular manner in connection with the knowledge about cleft-associated procedures in the affected children and other possible health burdens.

\section{CONCLUSION}

- The highest percentage of instability in the determined threshold of wave $\mathrm{V}$ between individual diagnostic periods occurred in the group of children with cleft palate or cleft palate and cleft lip;

- In the group of children with Down syndrome, it was observed that the instability of results of ABR tests decreased over time with subsequent tests in consecutive diagnostic periods;

- In the group of children with other diseases or damage to the nervous system, it is worth noting that the highest percentage of the lack of stable thresholds for wave V in the ABR study was observed between the 1st and 2nd as well as between the 1st and 4th diagnostic periods. The results of this observation therefore indicate that in the 1st diagnostic period children from this group repeatedly had results which to a large extent required verification, and repetition of test;

- In the group of children with congenital cytomegalovirus there was a low percentage of instability of results;

- Although the ABR test is a diagnostic standard, in particular groups of patients this study is burdened with high variability of measurement results in subsequent diagnostic periods. Such a group of patients are children with cleft palate or cleft lip and cleft palate; this must therefore receive particular attention in treatment planning;

- In selected groups at risk of hearing loss, due to the high percentage of children with hearing impairment (70\%), the validity of performing newborn hearing screening tests was confirmed. 


\section{REFERENCES}

1. Kocoń S., Wiatr A., Stręk P., Hartwich P., Ziarno R. et al.: Analysis of diagnostic-therapeutic results after the first year of life in children of hearing disturbance risk groups. Otolaryngol Pol, 2018; 72(3): 11-18.

2. Kochanek K.: Otolaryngologia Kliniczna. Red.: K. Niemczyk, D. Jurkiewicz, J. Składzień, Cz. Stankiewicz, W. Szyfter, Warszawa 2014: 55-69.

3. Pucher B., Jończyk-Potoczna K., Jakubczyk-Szymańska K. et al.: Zdrowa mama, zdrowy noworodek-czynniki ryzyka uszkodzenia słuchu u niemowląt w materiale Kliniki Otolaryngologii Dziecięcej Uniwersytetu Medycznego im. K. Marcinkowskiego w Poznaniu. Nowiny Lekarskie, 2012; 81(4): 311-315.

4. Kocoń S., Wiatr M., Stręk P., Wiatr A., Grudzień-Ziarno A. et al.: Analysis of difficulties occurring during the early auditory screening in children. Otolaryngol Pol, 2016; 70(4): 47-54.

5. Sato T., Nakazawa M., Takahashi S., Mizuno T., Ishikawa K. et al.: Outcomes of regional-based newborn hearing screening for 35,461 newborns for 5 years in Akita, Japan. Int J Pediatr Otorhinolaryngol., 2020; 131: 109870. Epub 2020 Jan 10.

6. Umehara T., Hosokawa S., Kita J.Y., Takahashi G., Okamura J. et al.: Risk Factors and Prognostic Factors of Hearing Impairment in Neonatal Intensive Care Unit-Treated Infants. Audiol Neurootol., 2019; 24(2): 84-89. Epub 2019 May 27.

7. Wykorzystanie słuchowych potencjałów wywołanych z pnia mózgu w diagnostyce systemu słuchowego człowieka. W: Podstawy inżynierii biomedycznej. Red.: J. Bułka, A. Izworski, I. Wochlik, R. Tadeusiewicz, P. Augustyniak, Wydawnictwa Naukowe AGH, 2009: 205-214.

8. Beswick R., Driscoll C., Kei J., Khan A., Glennon S.: Which risk factors predict postnatal hearing loss in children? J Am Acad Audiol., 2013; 24(3): 205-213.

9. Beswick R., Driscoll C., Kei J.: Monitoring for postnatal hearing loss using risk factors: a systematic literature review. Ear Hear., 2012; 33(6): 745-756.

10. Radziszewska-Konopka M.: Program Powszechnych Przesiewowych Badań Słuchu u Noworodków w Polsce organizowany przez Fundację Wielka Orkiestra Świątecznej Pomocy. Audiofonologia, 2002; 21.

11. Spivak L., Sokol H.: Beyond Newborn Screening: Early Diagnosis and Management of Hearing Loss in infants. Advances in Neonatal Care, 2005; 5(2): 104-112.

12. Bułka J., Izworski A.: Specyfika analizy sygnałów biomedycznych na przykładzie słuchowych potencjałów wywołanych. Pomiary, Automatyka, Robotyka., 2011; 12: 15.

13. Ciorba A., Hatzopoulos S., Corazzi V., Cogliandolo C., Aimoni C. et al.: Newborn hearing screening at the Neonatal Intensive Care Unit and Auditory Brainstem Maturation in preterm infants. Int J Pediatr Otorhinolaryngol., 2019; 123: 110115. Epub 2019 May 7.
14. Knaus V., Mühler R., Verhey J.L.: Determination of hearing thresholds in children using auditory brainstem responses: Influence of sedation and anaesthesia on quality and measurement time. HNO, 2019; 67(8): 584-589.

15. Schieve L.A., Boulet S.L., Boyle C., Rasmussen S.A., Schendel D.: Health of children 3 to 17 years of age with Down syndrome in 1997-2005. National Health Interview Survey. Pediatrics, 2009; 123: 253-260.

16. Pellegrinelli L., Galli C., Primache V., Alde' M., Fagnani E. et al.: Diagnosis of congenital CMV infection via DBS samples testing and neonatal hearing screening: an observational study in Italy. BMC Infect Dis., 2019; 19(1): 652.

17. Wang C., Chen R.J., Zhou Z.: Characteristics of secretory otitis media in children with cleft palate and timing of intervention of tympanic membrane. Lin Chung Er Bi Yan Hou Tou Jing Wai Ke Za Zhi, 2019; 33(7): 647-650.

18. Sundman H., Flynn T., Tengroth B., Lohmander A.: ABR Thresholds in Infants Born With CLP and OME and Infants With OME. Int J Pediatr Otorhinolaryngol, 2016; 81: 21-25.

19. Frezza S., Catenazzi P., Gallus R., Gallini F., Fioretti M. et al.: Hearing loss in very preterm infants: should we wait or treat? Acta Otorhinolaryngol Ital., 2019; 39(4): 257-262.

20. Arnouts L., Van Mechelen K., Laroche S., Meuwissen M., Boudewyns A. et al.: Non-primary CMV infection not always innocent. A case-report and literature review. Acta Clin Belg., 2020; $1-5$.

21. Cianfrone F., Mammarella F., Ralli M., Evetovic V., Pianura C.M. et al.: Universal Newborn Hearing Screening Using A-TEOAE and A-ABR: The Experience of a Large Public Hospital. Neonatal Perinatal Med., 2018; 11(1): 87-92.

22. Hrnčić N., Hatibović H., Goga A., Hodzić D.: Does an early discharge of a newborn influence the success of the newborn hearing screening in developing countries? A hospital based study. Med Glas (Zenica)., 2019; 16(2).

23. Escobar-Ipuz F.A., Soria-Bretones C., García-Jiménez M.A., Cueto E.M., Torres Aranda A.M. et al.: Early Detection of Neonatal Hearing Loss by Otoacoustic Emissions and Auditory Brainstem Response Over 10 Years of Experience. Int J Pediatr Otorhinolaryngol., 2019; 127.

24. Cikrikci S., Deni Z.H., Gülsen S.: Comparison of hearing screening results of Syrian refugees and Turkish newborns. Int J Pediatr Otorhinolaryngol, 2020; 135: 110095.

25. Fujita A., Hyde M.L., Alberti P.W.: ABR Latency in Infants: Properties and Applications of Various Measures. Acta Oto-Laryngologica, 1992; 111(1): 53-60.

Word count: 4279 Tables: 2 Figures: 3 References: 25

Access the article online: DOI:10.5604/01.3001.0014.3322 Table of content: https://otolaryngologypl.com/resources/html/articlesList?issueld=0

Corresponding author: Sebastian Kocoń; Chair and Clinic of Otolaryngology, Jagiellonian University, Collegium Medicum, Cracow; ]akubowskiego street 2, 30-688 Cracow, Poland; E-mail: sebastian.kocon@uj.edu.pl

Some right reserved: Polish Society of Otorhinolaryngologists Head and Neck Surgeons. Published by Index Copernicus Sp. z o.o.

Competing interests: The authors declare that they have no competing interests

The content of the journal "Polish Society of Otorhinolaryngologists Head and Neck Surgeons” is circulated on the basis of the Open Access which means free and limitlessaccess toscientific data.

This This material is available under the Creative Commons - Attribution-NonCommercial 4.0 International (CC BY-NC 4.0). The full terms of this license are available on: https://creativecommons.org/licenses/by-nc/4.o/legalcodee

Cite this article as: Kocon S., Skorkiewicz K., Strek P., Skladzien ]., Hartwich P., Ziarno R., Tomik ].: Stability of ABR Wave V Threshold in Early Hearing Diagnostics in Children from Selected Croups at Risk of Congenital Hearing Loss; Otolaryngol Pol 2020; 74: 1-9; DOI: 10.5604/01.3001.0014.3322 (Advanced online publication) 
